\title{
A Painting Teaching Mode Based on STEM Theory
}

\author{
https://doi.org/10.3991/ijet.v13i08.9048 \\ Chang Pan \\ University of Science and Technology Liaoning, Anshan, Liaoning \\ kdpc $0412 @ 126 . \mathrm{com}$
}

\begin{abstract}
Painting teaching is of great significance in cultivating students' observation, imagination, creativity and personality. However, due to the outdated teaching methods, the traditional painting teaching mode makes it impossible to effectively combine relevant knowledge and painting skills during the teaching process and therefore makes it difficult to achieve the overall purpose of painting teaching. With this regard, a STEM (Science, Technology, Engineering, Mathematics) teaching method was proposed in this study and introduced into the entire painting teaching process. It includes three painting teaching programs, namely scientific inquiry, engineering practice, and communication enhancement and integrates "Painting 3D" software of Windows 10 for teaching. The teaching practice of the STEM teaching mode in the painting course proved that the teaching mode can effectively improve students' ability to combine the learned theoretical knowledge of painting with the actual operation. At the same time, it can enhance students' interest in learning and cultivate students' comprehensive capacity.
\end{abstract}

Keywords-STEM Theory, Painting teaching, "Painting 3D" software

\section{Introduction}

Humans have used painting to express themselves long before they used characters. Painting has also been preserved as an art form and is being taught in schools. However, most students cannot effectively combine their learned knowledge with their ideas after learning traditional painting art courses. Those students who lack support and encouragement show limited improvements in their painting skills and ultimately lose their interest in painting [1]. Therefore, the traditional method for teaching painting must be reformed and a new painting teaching mode that allows students to use their imagination in their learning process, utilize various approaches to learn painting skills, and comprehensively develop their painting abilities must be devised.

Primary and middle schools as well as colleges in China are still adopting the traditional face-to-face teaching mode for delivering painting courses. Although such traditional teaching mode can effectively and systematically impart painting knowledge and develop the painting skills of students, these students usually perceive such knowledge transfer process dull and boring. Moreover, the painting knowledge learned in classrooms show certain differences from practical painting skills [2]. In- 
stead of completely replacing the traditional painting teaching mode, this paper aims to introduce the Science, Technology, Engineering, and Mathematics (STEM) teaching method [3] in teaching painting, which focuses on the practical application of knowledge and allows students to deepen their knowledge through inquiry and application. This teaching method also allows students to treat problem orientation as their learning objective, which puts forward some requirements for the entire teaching mode [4]. In this study, the STEM-based teaching mode was utilized to teach a painting course to provide references for painting and other art courses.

\section{State of the art}

Two teaching modes are usually applied in painting courses. On the one hand, the traditional teaching mode is based on the classroom teaching of teachers and the learning and visitation activities of students. On the other hand, the heuristic teaching mode teaches students through heuristic teaching. Although the traditional teaching mode systematizes the entire knowledge architecture, this method is considered outdated and unable to organically combine relevant painting knowledge with painting skills or achieve the purposes of painting teaching. To address these problems, many other teaching modes have been derived from the heuristic teaching mode, including learning guide teaching mode, multimedia teaching mode, and STEM-based teaching mode. This research specifically focuses on the STEM-based teaching mode, which originated from the US. To break the boundaries among different disciplines, the STEM-based teaching mode solves the related problems by using knowledge from multiple fields. Therefore, this teaching mode can be used in interdisciplinary and comprehensive discipline teaching and has often been applied in the engineering interdisciplinary field. However, when applied in teaching painting, the STEM-based teaching mode must combine theory with practice to hone the professional theoretical knowledge and painting skills of students [5].

Foreign studies on the STEM-based teaching mode have proposed multiple teaching modes, including the 5E teaching mode, $6 \mathrm{E}$ teaching mode, and PIRPOSAL model. The 5E teaching mode [6] acts as the foundation of the STEM-based teaching mode, which main principles include engagement, exploration, explanation, elaboration, and evaluation. This teaching mode has been widely applied in Maryland, Baltimore in the US. The local education department of Maryland also integrated the 5E teaching mode in its primary and middle school classroom teaching. Meanwhile, the $6 \mathrm{E}$ teaching mode is an advanced teaching mode based on the $5 \mathrm{E}$ teaching mode after Kramer [7] introduced "enrichment" as an additional principle as he argued that the entire knowledge scope of students can be improved by enriching their classroom knowledge. Wells [8] proposed the PIRPOSAL model, a comprehensive STEM-based teaching mode that combines the features of the problem-orientated teaching mode. This mode places problems at the core of the teaching process and implements stage teaching for the whole teaching framework. Although the PIRPOSAL model guides students in their knowledge learning process, this method does not explore the teaching objective, cultivation method, and teaching plan. Thus, the PIRPOSAL model 
cannot be considered a complete STEM-based teaching mode. Smith et al. [9] established a learning community in Howard University and engage in the scholarship of teaching and learning by learning about teaching, reflecting on their practice, and demonstrating competence or knowledge of effective teaching. Some activities being held in this community include interdisciplinary seminars, linked courses, teaching experiments, and biweekly meetings, which collectively form a process of learning and reflection that is supported by the community members. Meanwhile, the faculty learning community (FLC) activity evaluation identifies FLC as an effective mechanism for strengthening teaching and learning in STEM disciplines.

Chinese research on the STEM-based teaching mode is still in its theoretical stage. However, only few studies have examined courses that are delivered based on the STEM-based teaching mode. By using STEM-based teaching mode as its core concept, $\mathrm{Wu}$ [9] examined the innovative technical practices of primary and middle schools, including Arduino robot programming, to explore the STEM-based teaching mode. Ma [10] reviewed the foreign studies on the STEM-based teaching mode and considered the integrated features of the 5E teaching mode to develop the UIRDE teaching mode, which is particularly suitable for Chinese schools. This teaching mode comprises five parts, namely, problem understanding, literature learning, investigation, mode construction, and result remodeling. Ma then tested the feasibility of this mode by applying UIRDE in a teaching case. Tang [11] argued that the STEM-based teaching mode must apply learning theories and emphasize the practical application of knowledge in the learning process. A repeated teaching practice was also conducted to improve the STEM-based teaching mode and to promote the combination of knowledge and practice.

\section{$3 \quad$ STEM-based painting teaching mode}

The main purpose of the STEM-based painting teaching mode is to link STEM teaching theory with the painting teaching practice. Fig. 8 presents the methodological theoretical model diagram of this teaching mode.

As shown in Figure 8, the STEM-based painting teaching mode acts as the foundation for linking the abstract layer with the concrete layer. The STEM-based teaching mode has two types of construction methods. The first type is the deductive method, which starts from the top to the bottom. The relation between theory and teaching practice reveals that the STEM teaching theory must be investigated in depth before constructing the deductive method. Afterward, the STEM-based painting teaching mode must be investigated based on theory. The success of this teaching mode is then verified by applying STEM-based painting teaching mode in painting teaching practice, and the correctness of the STEM teaching theory is eventually verified. The second method is the inductive method, which begins from the bottom to the top. By 


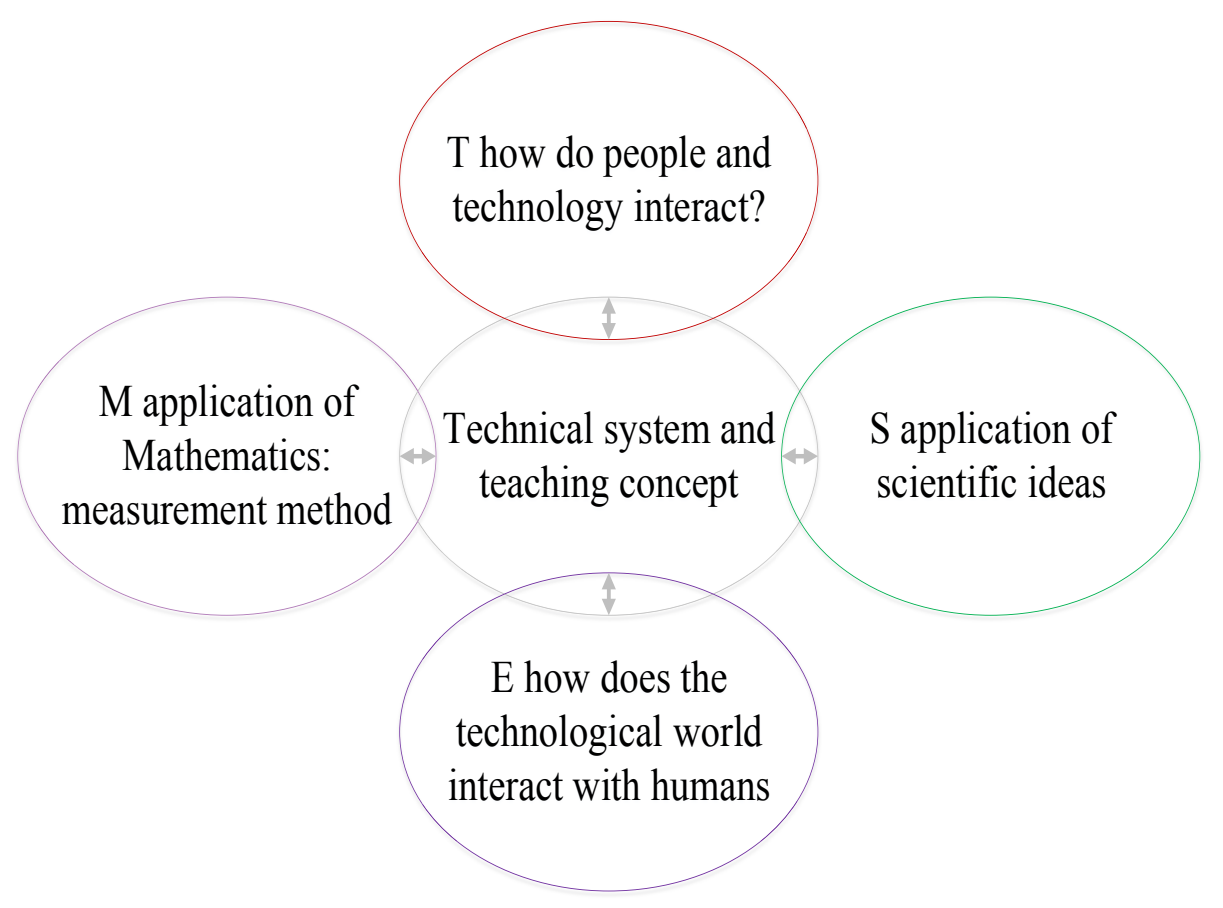

Fig. 1. Methodological theoretical model diagram of the STEM-based painting teaching mode

identifying an excellent STEM-based teaching mode and teaching practice, this construction method eventually abstracts a painting teaching mode that is suitable for teaching painting courses. This painting teaching mode is then theoretically verified by using STEM teaching theory, and the STEM-based painting teaching mode is constructed through the teaching program and the teaching mode.

\subsection{STEM-based painting teaching mode}

The STEM-based painting teaching mode mainly comprises five teaching elements, namely, teaching objective, teaching program, teaching resource, evaluation method, and role of teachers and students. In this teaching mode, the painting teaching program is treated as the subject of implementation. This mode aims to cultivate the comprehensive quality of students by using the teaching objective as a guide. Fig. 2 presents the basic structure of the STEM-based painting teaching mode, where the interaction between each part and element can significantly improve the comprehensive painting quality of students. 


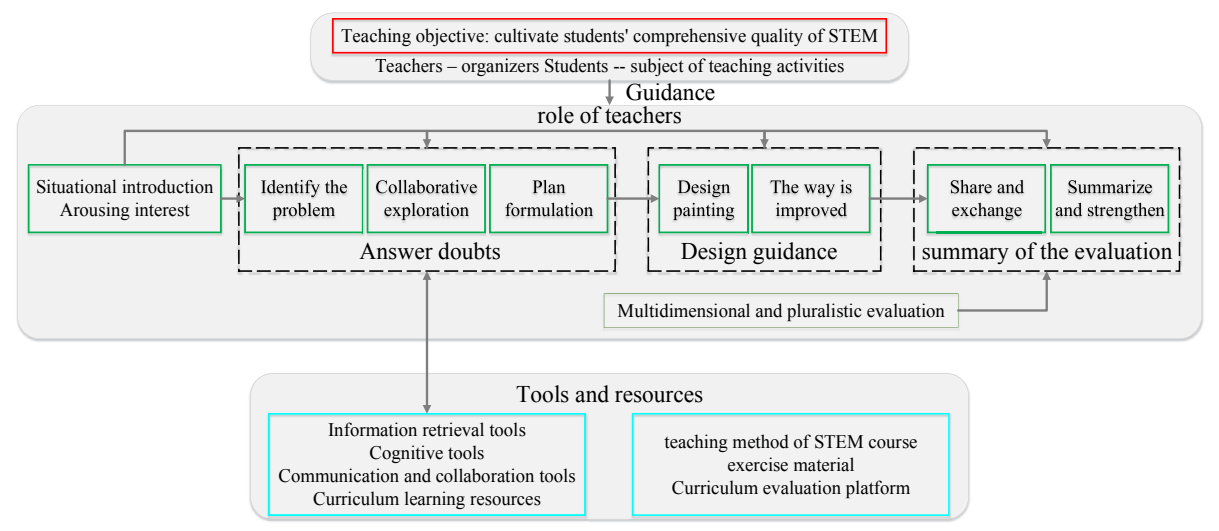

Fig. 2. Basic structure of the STEM-based painting teaching mode

\subsection{STEM-based painting teaching program}

Fig. 3 presents the diagram of STEM-based painting teaching program, which can mainly be divided into three stages, namely, scientific inquiry, engineering practice, and communication enhancement. These stages can effectively facilitate the communication and fusion between students and teachers and between students and knowledge.

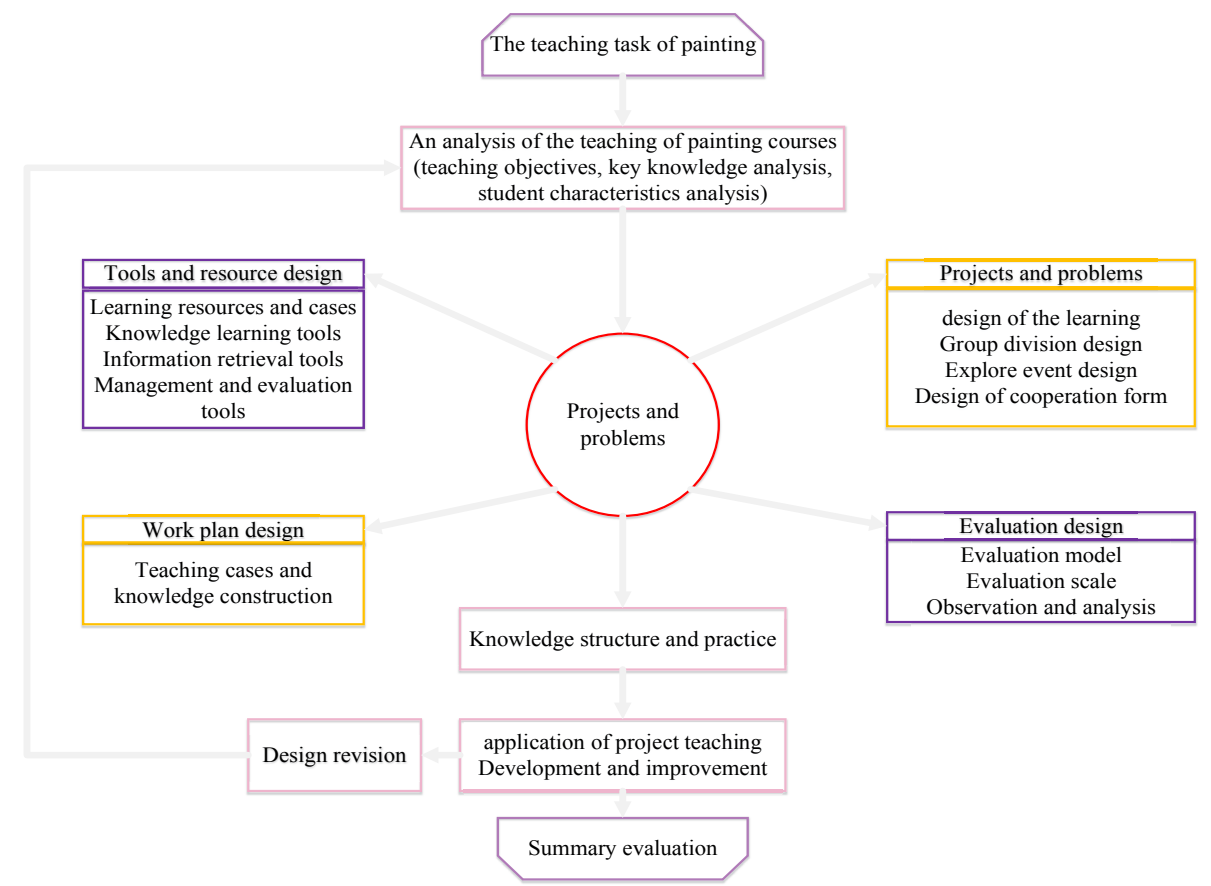

Fig. 3. STEM-based painting teaching program 
The STEM-based painting teaching program regards the student learning painting course as its objective. The teacher aims to help his/her students learn and manage their learning activities. The role of the teacher differs across each stage of the painting teaching program. Specifically, in the scientific inquiry stage, the teacher must answer the questions and solve the problems encountered by his/her students throughout the whole course. The teacher may also serve as a director that directs the scientific inquiry learning of his/her students. In the engineering practice stage, the teacher acts as a technical instructor and checks whether his/her students adopt rational painting skills. In the communication enhancement stage, the teacher acts as an evaluator and director of the paintings of his/her students. These stages can be further decomposed into the following parts:

1. Situation introduction. Given that the STEM-based teaching mode is an inquirybased teaching form, a favorable learning condition must be established for the students. For example, a foundation for learning composition form can be established by visiting sculpture and art exhibitions and by choosing the optimal composition angle and picture proportion in real situations.

2. Problem recognition. Problem-oriented teaching is the major teaching form in the STEM-based teaching mode. Therefore, the students must understand the problems being faced by students throughout the learning process. If these students encounter some doubts about their painting skills in the learning process, then they can ask their teachers and solve their problems afterward.

3. Cooperative inquiry. Cooperative inquiry closely follows problem recognition. After the students understand the object of their painting, they can cooperate with one another or determine the most appropriate solutions through an intra-group exchange of ideas.

4. Scheme making. After cooperative inquiry, a preliminary scheme must be developed. After confirming the direction of the STEM-based teaching mode, the influence of multiple factors in the composition design must be considered.

5. Painting design. After confirming the basic scheme and space composition form, the students must design and complete their paintings according to their developed scheme.

6. Sharing and exchange. After completing their paintings, the students must display their works on a platform. Students can learn about the advantages of one another and identify their own shortcomings and defects based on the suggestions of others.

7. Summarization and enhancement. The final requirement of the STEM-based teaching mode is to help students gain knowledge from learning. These students must sum up the knowledge and information that they have gained through exchanges to lay a foundation for improving their painting skills. 


\section{Teaching Case and Teaching Effect}

The STEM-based painting teaching mode was then applied in a teaching case. Painting was used as an example to explore the practical teaching effect of the STEMbased painting teaching mode.

\subsection{Teaching case}

Painting is a very complex learning process. Given the abundant amount of painting knowledge that they must learn, the students must have a strong painting ability before taking a painting course. A painter must do a sketch before attempting to paint a picture. Afterward, s/he must create a solid color foundation for his/her painting. The application of the STEM-based painting teaching mode can effectively encourage the participation of students in their learning and allow them to grasp basic painting skills.

Situation introduction . Situation creation: In situation introduction, the teacher leads his/her students to visit art exhibitions and observe paintings. When visiting a painting exhibit, the students must understand the foundation of famous painters. For example, coloring expresses the language of the painter and demonstrates his/her emotions and ways of thinking. Painters have different feelings for each situation. Therefore, when selecting painting colors, painters may choose among opaque coloring, opaque broken coloring, or transparent broken coloring. Therefore, students must closely inspect the differences among these coloring methods. Main function navigation zone is above the canvas is, including tool-3D object, sticker, text, effect, canvas. The auxiliary function zone is at the upper right: stick, cancel, historical records, and rework. Visual function choice is below the canvas: reset view, customize vision size, edit pattern (plane), and view in 3D form. Figs. 4 and 5 show situation introductions 1 and 2 , respectively.

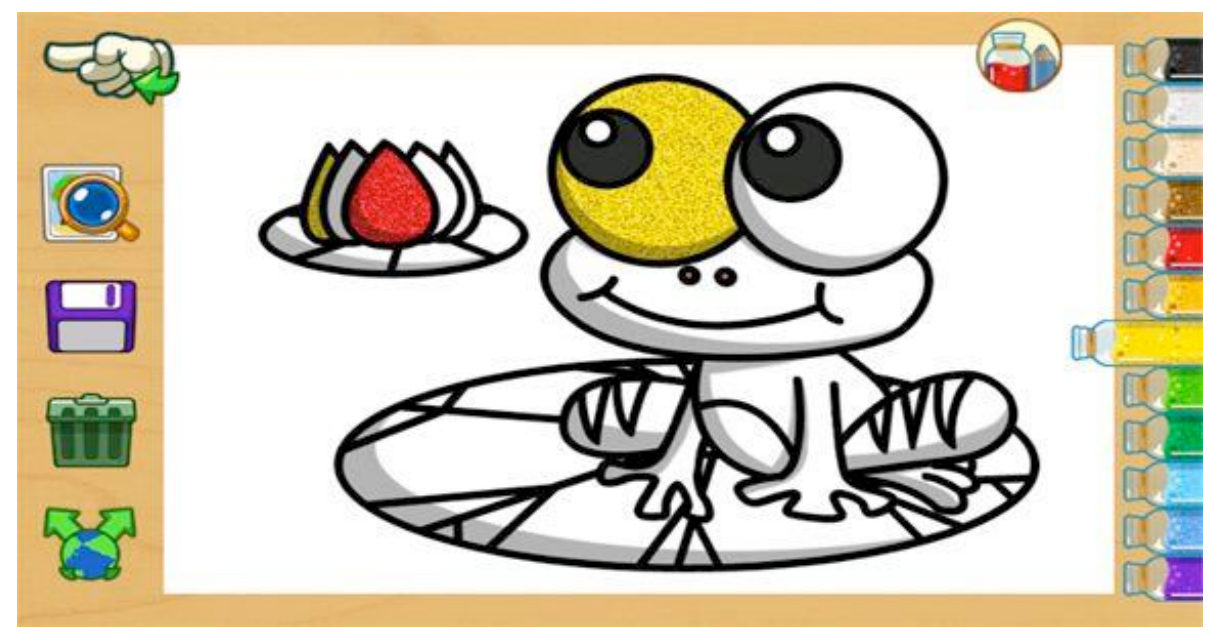

Fig. 4. Situation introduction 1 of painting coloring 


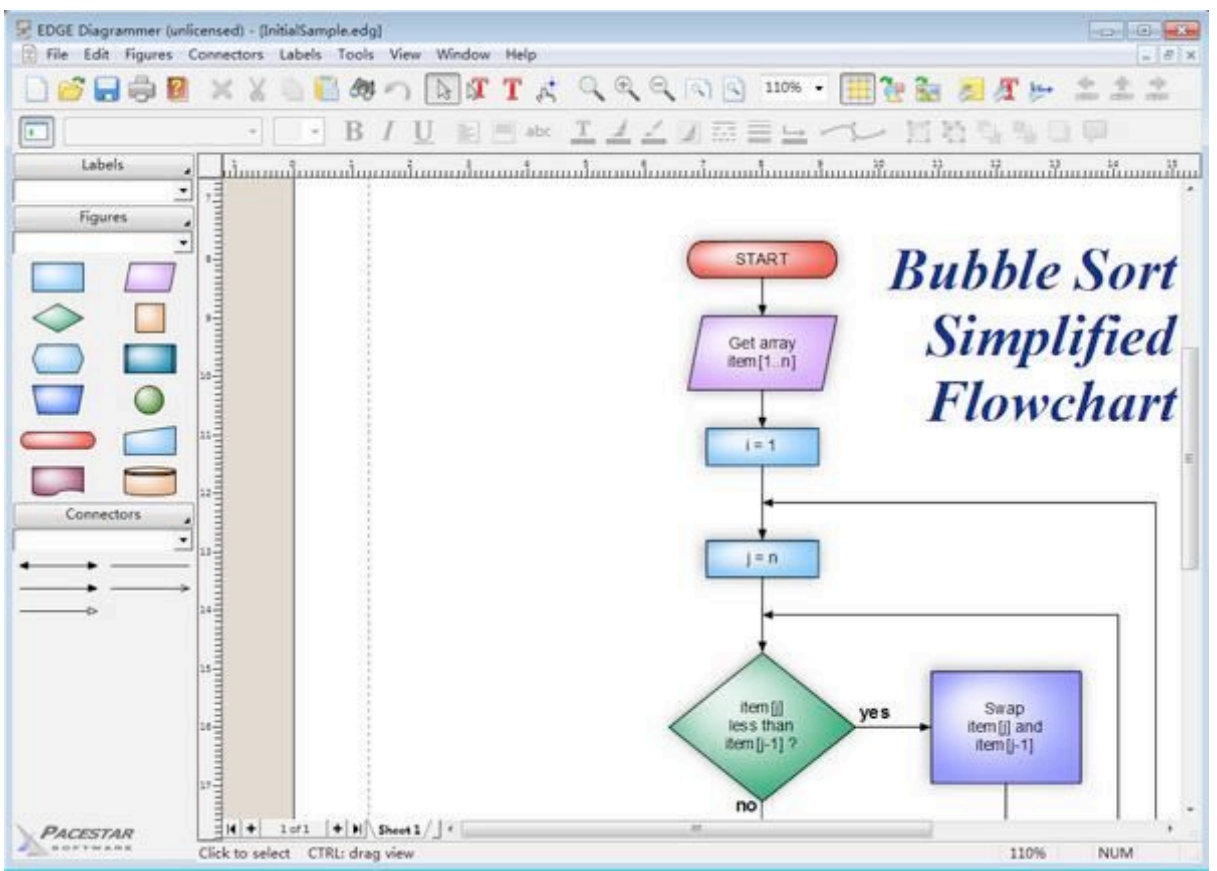

Fig. 5. Situation introduction 2 of painting coloring

Inquiry link. After listening to the explanations of their teacher, the students utilize their own knowledge to devise their own painting coloring method. After the exhibition, these students were asked to practice different coloring methods, explore their advantages and disadvantages, and conduct "sticking" in 3D painting.

As shown in Fig. 6, after the students chose a "3D object," the following reset models and objects (from left to right) would be shown on the right side: 3D model: man, woman, god, cat and fish; 3D object: cube, sphere, capsule shape, ring, and cone; and 3D scrawling: sharp edge and soft edge. These students may DJY 3D models according to their hobbies, choose the models that they like, and paint them on canvas. After completing their painting, these students may use the sticker tool of the main function navigation and embed lovely stickers in their models. Afterward, they may choose the 3D form in the vision option to check these models. 


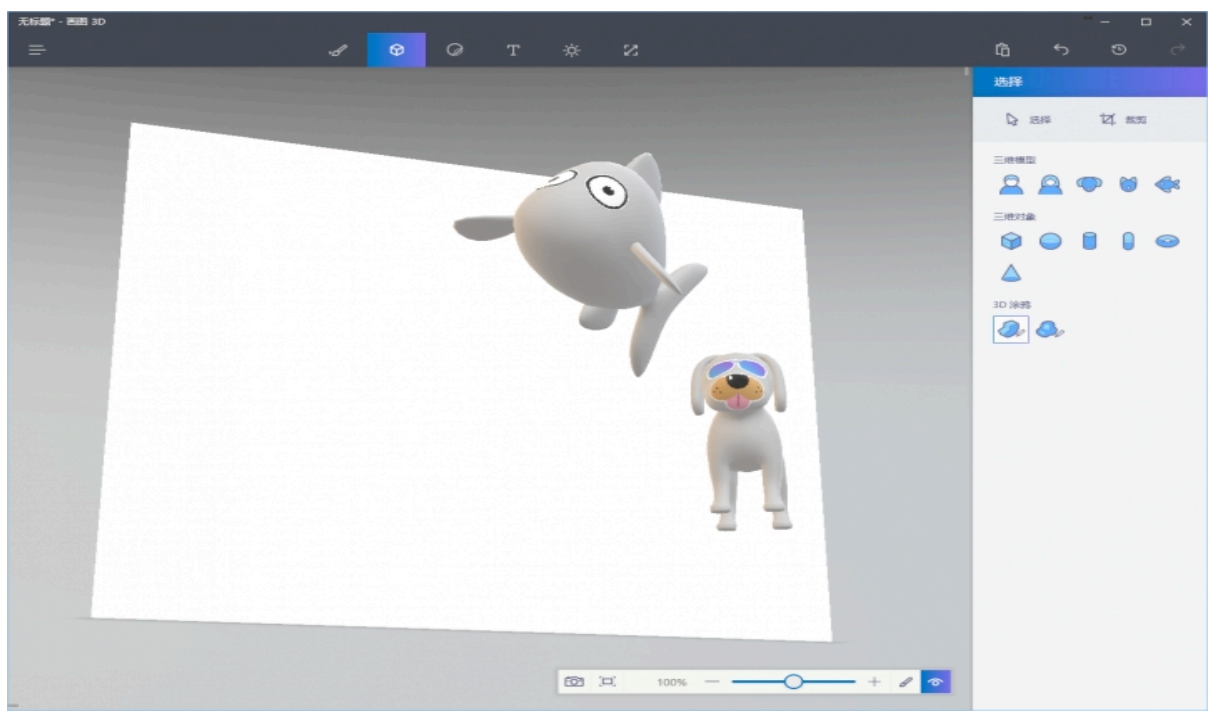

Fig. 6. Students' inquiry of paintings - 3D object selection

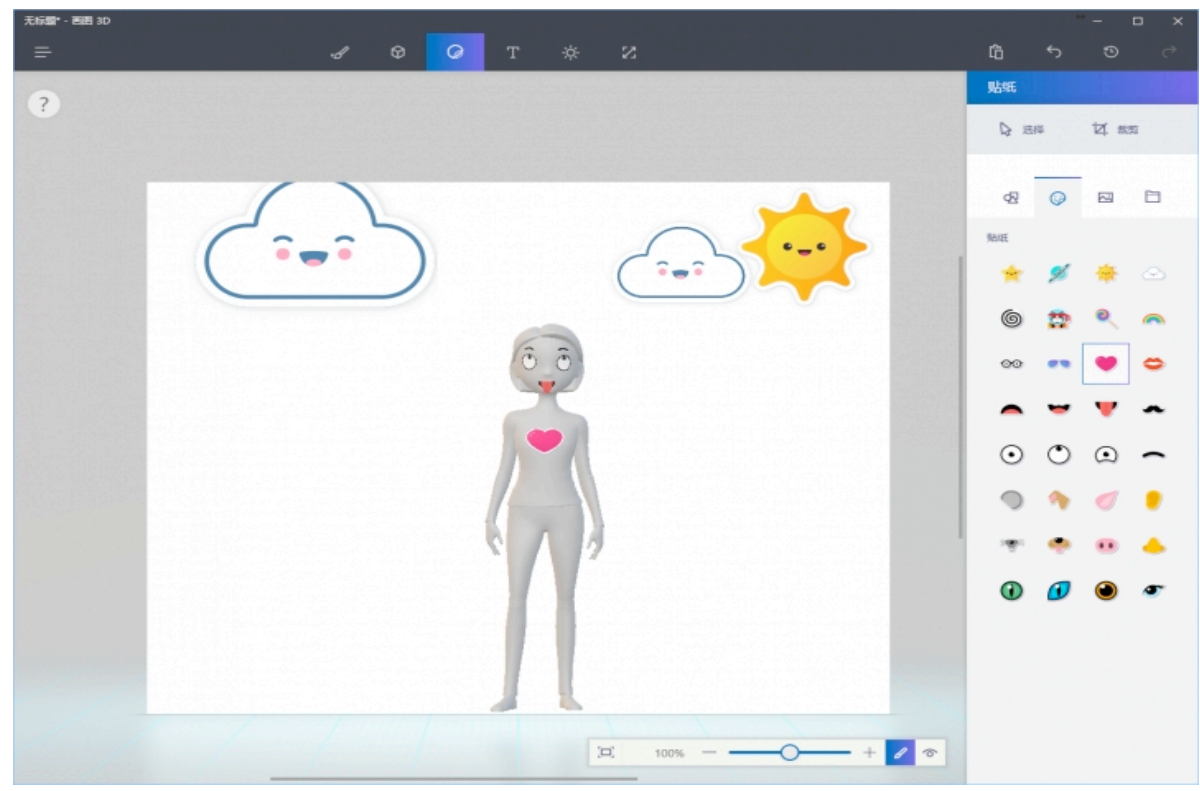

Fig. 7. Students' inquiry of paintings - Sticker

As shown in Fig. 7, similar to 3D object, a "sticker" has some preset contents, such as a five-pointed star, sun, and cloud. The students can choose the stickers to be included in their models based on their needs. The size of these "stickers" can also be adjusted and transformed into a 3D form. 


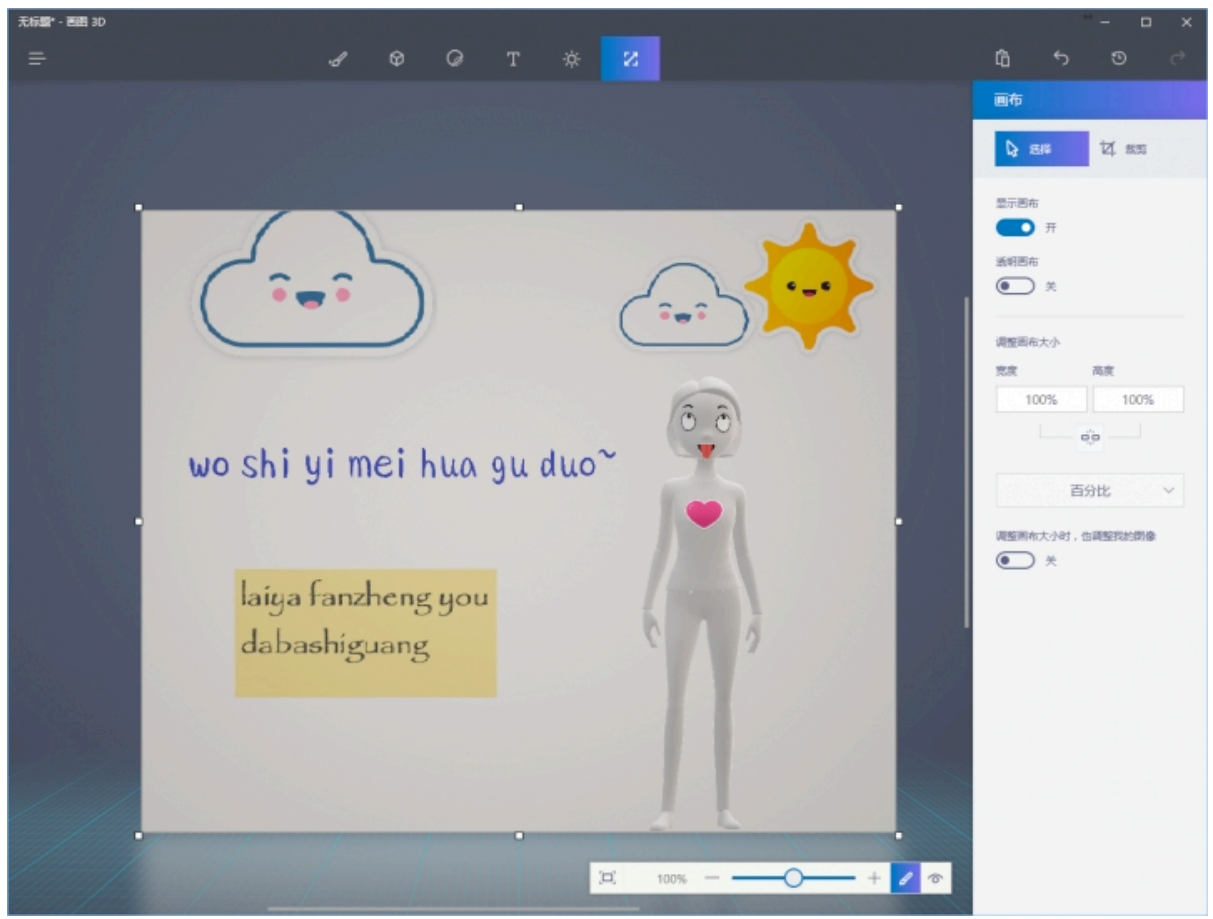

Fig. 8. Students' inquiry of paintings - Canvas adjustment

As shown in Fig. 8, if the students want to adjust the size of the canvas, then they may choose "canvas" in main function navigation and then adjust the canvas as needed in the right detailed function zone.

Explanation link. After students explored the different painting coloring options, the teachers observed their application of painting coloring and offered them some suggestions. Meanwhile, the students may tell the teacher about the problems they have encountered during the painting coloring process, and then the teacher can guide them in solving their problems.

Discussion link. After coloring their paintings, the students spontaneously formed groups to discss and share their feelings, analyze the problems faced by the other team members, and propose the appropriate solutions.

Summarization and evaluation. After the group discussion, the students wrote their reports and completed their paintings. The teacher then evaluated these reports and paintings before proposing some suggestions for improving the painting level of the students.

\subsection{Teaching effect}

Two rounds of experiments were conducted, where the STEM-based painting teaching mode was only applied in the second round. A total of 25 students participated in each round. These students were further classified into five groups, with each 
group having five members. A student could not take part in both rounds of experiments. A questionnaire survey was conducted to investigate the learning effect of the STEM-based painting teaching mode. The investigation focused on two aspects, namely, the painting scheme and the painting works of the students. Table 1 presents the painting scheme applied by the students in the second round of the experiment.

Table 1. Design of the entire painting scheme adopted by the students in the second round of the experiment

\begin{tabular}{|c|c|c|c|c|c|}
\hline Group & $\begin{array}{c}\text { Condition } \\
\text { satisfaction }\end{array}$ & $\begin{array}{c}\text { Complete and } \\
\text { correct scheme }\end{array}$ & $\begin{array}{c}\text { Conformity to } \\
\text { painting concept }\end{array}$ & Realizability & Score \\
\hline 1 & Very agree(25) & Very agree(25) & Very agree(25) & More agree(20) & 95 \\
\hline 2 & Very agree(25) & Very agree(25) & Very agree(25) & Very agree(25) & 100 \\
\hline 3 & Very agree(25) & Basic agree(15) & Very agree(25) & Very agree(25) & 90 \\
\hline 4 & Very agree(25) & Very agree(25) & More agree(20) & Very agree(25) & 95 \\
\hline 5 & Very agree(25) & More agree(20) & More agree(20) & Very agree(25) & 90 \\
\hline Average Scores & 25 & 22 & 23 & 24 & 94 \\
\hline $\begin{array}{c}\text { Average Scores of First } \\
\text { Round }\end{array}$ & 25 & 21 & 21 & 21 & 88 \\
\hline
\end{tabular}

The students in both rounds of experiments received a perfect score for their painting schemes and showed improvements in the correctness, completeness, and realizability of their schemes as well as their conformity to the painting concept.

The results of the evaluation on the painting works of the students in the second round of experiment are summarized in Table 2.

Table 2. Evaluation of the painting works of students in the second round of the experiment

\begin{tabular}{|c|c|c|c|c|c|}
\hline Group & $\begin{array}{c}\text { Requirement } \\
\text { satisfaction }\end{array}$ & Clear layout & $\begin{array}{c}\text { Emotion con- } \\
\text { veying }\end{array}$ & Art beauty & Score \\
\hline 1 & Very agree(25) & Very agree(25) & Very agree(25) & More agree(20) & 95 \\
\hline 2 & Very agree(25) & More agree(20) & More agree(20) & Very agree(25) & 90 \\
\hline 3 & Very agree(25) & Very agree(25) & Very agree(25) & Very agree(25) & 100 \\
\hline 4 & Very agree(25) & More agree(20) & More agree(20) & More agree(20) & 85 \\
\hline 5 & More agree(20) & More agree(20) & More agree(20) & Very agree(25) & 85 \\
\hline Average Scores & 24 & 22 & 23 & 23 & 91 \\
\hline $\begin{array}{c}\text { Average Scores of } \\
\text { First Round }\end{array}$ & 22 & 18 & 19 & 21 & 80 \\
\hline
\end{tabular}

Table 2 shows that the STEM-based painting teaching mode has improved the painting works of the students in both groups. Apart from increasing the learning level of these students, this teaching mode can also effectively promote their mastery of painting knowledge and painting skills. The scores for "requirement satisfaction," "clear layout," "emotion conveying," and "art beauty" in the second round of the experiment are higher than those obtained in the first round of the experiment. 


\section{Conclusions}

Compared with the traditional painting teaching mode, the STEM-based painting teaching mode can effectively improve the learning ability of students and promote the all-around development of students and teachers [9]. The other advantages of this teaching mode are summarized as follows:

1. The STEM-based painting teaching mode can effectively combine painting knowledge and practical painting operation, cultivate the ability of students to combine practical operation ability with theoretical knowledge, and allow teachers to integrate theory with practice throughout the entire teaching process. Therefore, this method plays an indispensable role in enhancing the comprehensive ability of students.

2. The STEM-based painting teaching mode can effectively promote the knowledge seeking ability and exploration spirit of students. These students can devise solutions to their problems through material consulting and group discussion. This teaching mode can also allow students to practice in learning and learn in practice as well as develop their good learning habits.

3. The role and status of teachers change in the STEM-based painting teaching mode. Moreover, the students do not merely act as "knowledge absorbers," while the teachers can gain more experience from their teaching and consequently improve their teaching abilities. This painting teaching mode can also strengthen the bond between the teachers and students and allow them to achieve progress together.

\section{References}

[1] Tang, M. Self-Discovery in the Pursuit of Value of Art: Analysis and Experience of My Course of Painting Creation and Teaching. Journal of Tianjin Academy of Fine Arts, 2015. vol. 2, pp. 92-93.

[2] Pan, C. Design and Application of Multi-screen VR Technology in the Course of Art Painting. International Journal of Emerging Technologies in Learning, 2016, vol. 11(9), pp. 56-58. https://doi.org/10.3991/ijet.v11i09.6126

[3] Henriksen, D. Full STEAM Ahead: Creativity in Excellent STEM Teaching Practices. Steam Journal, 2014, vol. 1(2), pp. 1-9. https://doi.org/10.5642/steam.20140102.15

[4] Hardré, P.L., Ling, C., Shehab, R.L., et al. Designing and evaluating a STEM teacher learning opportunity in the research university. Eval Program Plann, 2014, vol. 43, pp. 7382. https://doi.org/10.1016/j.evalprogplan.2013.11.002

[5] Hazzan, O., Ragonis, N. STEM teaching as an additional profession for scientists and engineers: the case of computer science education. ACM Technical Symposium on Computer Science Education, 2014, pp. 181-186.

[6] Laveria, F. Hutchison. Addressing the STEM Teacher Shortage in American Schools: Ways to Recruit and Retain Effective STEM Teachers. Action in Teacher Education, 2012, vol. 34(5-6), pp. 541-550. https://doi.org/10.1080/01626620.2012.729483

[7] Kramer, D. Universities seek culture change for improved STEM teaching. Physics Today, 2011, vol. 64(11), pp. 22-25 https://doi.org/10.1063/PT.3.1324 
[8] Wells, J.G. PIRPOSAL Model of Integrative STEM Education: Conceptual and Pedagogical Framework for Classroom Implementation. Technology \& Engineering Teacher, 2016, vol. 75(6), pp. 12-19.

[9] Smith, T.R., Mcgowan, J., Allen A R, et al. Evaluating the Impact of a Faculty Learning Community on STEM Teaching and Learning. Journal of Negro Education, 2008, vol. 77(3), pp. 203-226.

[10] Ma, N. An Attempt of Science Education Based on UIRDE Teaching Model — The Teaching Design of "Hybrid Breeding and Mutation Breeding". Bulletin of Biology, 2015, vol. 50(12), pp. 21-24.

[11] Tan, Y.W., Guo, L.T., Xie, Y.G., et al. Research on STEM Interdisciplinary Integration Model Based on Educational Artificial Intelligence. China Educational Technology, 2017, vol. 8, pp. 46-52.

\section{$7 \quad$ Author}

Chang PAN is a Lecturer in the University of Science and Technology Liaoning, Anshan 114051, China. (kdpc0412@126.com).

Article submitted 21 March 2018. Resubmitted 28 May 2018. Final acceptance 13 June 2018. Final version published as submitted by the authors. 